\title{
CLIMATE CHANGE AS THE NEWEST DETERMINANT OF CORPORATE RISK MANAGEMENT STRATEGIES OF MULTINATIONAL ENTERPRISES
}

\author{
Mykhailo Rushkovskyi ${ }^{1}$, Dmytro Rasshyvalov ${ }^{2}$
}

\begin{abstract}
This article aims to summarize and present the fundamental trends of the last decade related to climate change, as well as interstate and global economic cam-paigns to slow it down, which create a powerful new determinant for multinational enterprises (MNEs) in corporate governance, risk management and the sound man-agement of climate risks and opportunities. Methodology. The analysis is based on recent studies by leading international scientists such as the International Energy Agency and the Economist Intelligence Unit, authorized UN bodies, universities, and the MNE Task Force on Climate-related Financial Disclosures. The results of the analysis showed that climate risks and opportunities already have a clear monetary value and impact on MNE. Today's efficient business faces the need to build an effective system for managing such risks, which, in addition to its direct effect on MNE, will also be an important signal to stakeholders, which, in turn, can reduce the cost of capital raised and increase revenues level. Practical implications. For some EU countries, it will soon become mandatory to highlight climate risk management principles and approaches in annual reports. Internal models are being developed to show the impact of climate change on the business of MNEs (e.g. an increase of $1.5{ }^{\circ} \mathrm{C}, 2{ }^{\circ} \mathrm{C}, 4{ }^{\circ} \mathrm{C}$ in total temperature). A unified approach to climate risk management is therefore becoming a topic of great importance to MNEs and their stakeholders, including regulators, investors, shareholders, and society. Value/originality. The analysis provides an in-depth understanding of the main factors of climate-risk management for MNEs, as well as its practical implications arising in the global economy.
\end{abstract}

Key words: risk management strategies, climate change, risk management.

JEL Classification: D81, G32, Q54

\section{Introduction}

In 1992, the UN Framework Convention on Climate Change first raised the issue of climate change and its impact on the global economy. According to an analysis by the Intergovernmental Panel on Climate Change, Earth's surface temperature is projected to continue rising through the end of the 21st century; the global increase in average surface temperature between 2016 and 2035 compared to $1986-2005$ is likely to be between $0.3{ }^{\circ} \mathrm{C}$ and $0.7^{\circ} \mathrm{C}$. In addition, heat waves will occur more frequently, extreme precipitation will become more intense and frequent in many regions, and the oceans will continue to warm as sea levels rise.
However, the exact impact of these changes on climate and weather conditions is far from predictable. According to Rory Sullivan, Senior Research Fellow at the Centre for Climate Change Economics and Policy at the University of Leeds (UK), climate change risks must be assessed and managed in the same way as other risks, focusing on both probability and magnitude of impact (The Economist Intelligence Unit, 2015).

The global warming expected by 2050 is the result of past emissions; in other words, warming will occur even if further carbon emissions are stopped immediately. According to Nick Robins, co-director of the United Nations Environment Program's (UNEP) Sustainable Financial System

\footnotetext{
Corresponding author:

${ }^{1}$ Institute of International Relations of Taras Shevchenko National University of Kyiv, Ukraine

E-mail: rushkovskyi@gmail.com

ORCID: https://orcid.org/0000-0001-5929-4339

${ }^{2}$ Institute of International Relations of Taras Shevchenko National University of Kyiv, Ukraine

E-mail: rasshyvalovd@ukr.net

ORCID: https://orcid.org/0000-0002-1404-9302
} 
Study, once greenhouse gases are released into the atmosphere, climate change becomes almost irreversible; climate change will be very destructive in the first half of the 21st century (The Economist Intelligence Unit, 2015). Because of the delayed impact of carbon dioxide emissions, the full effects of greenhouse gases emitted today can only be felt some time after they are released into the atmosphere.

One of the key challenges for international financial markets is to properly quantify climate risks to support informed and effective capital allocation decisions. Accurate and timely disclosure of current and past operating and financial results of multinational enterprises (MNEs) is fundamental to meeting this challenge, but it is increasingly important to understand the risk management context by which financial results are achieved. The 2007-2008 financial crisis was an important reminder of the impact that weak corporate governance and risk management practices can have on asset values. This led to an increased demand from MNEs for transparency regarding their governance structures, strategies and risk management practices. Without proper information, investors and other stakeholders could misappropriate assets, leading to misallocation of capital.

One of the most significant and perhaps most misunderstood risks facing MNEs today is climate change. While it is generally recognized that continued greenhouse gas emissions will lead to further global warming, and that this warming could have devastating economic and social consequences, the exact timing and se-verity of the physical consequences are difficult to assess. The large-scale and long-term nature of the problem makes it unique, especially in the context of economic decision-making by international traders. As we know, many MNEs misunderstand the medium- and long-term consequences of climate change and therefore cannot take a holistic approach to decision-making today.

\section{The financial consequences of climate change}

However, the potential effects of climate change on MNEs are not just physical and only manifest in the long term. To halt the catastrophic effects of climate change in the 21 st century, 196 countries agreed in December 2015 to reduce greenhouse gas emissions and accelerate the transition to a low- carbon economy as part of the Paris Agreement (UN Framework Convention on Climate Change, 2015). Reducing greenhouse gas emissions involves moving away from fossil fuels and the physical assets associated with it. This, combined with rapid cost reductions and increased adoption of clean and energy-efficient technologies, could have significant short-term financial implications for MNEs that depend on the production and use of coal, oil, and natural gas. While such MNEs may face significant climate risks, they are not the only ones in this issue. In fact, climate risks and the expected transition to a low-carbon economy affect most sectors of the global economy. While the changes associated with the transition to a low-carbon economy pose significant risks, they also present significant opportunities for MNEs focused on combating and adapting to climate change.

For many investors, climate change presents significant financial risks and op-portunities. Fully meeting climate commitments will require the energy sector to invest $\$ 13.5$ trillion in energy efficiency and low-carbon technologies between 2015 and 2030, nearly 40\% of total energy sector investments. About 8.3 trillion USD is needed to improve energy efficiency in the transport, construction and industrial sectors, while most of the remaining investment is aimed at decarbonizing the energy sector. More than $60 \%$ of the total investment in generation is projected to be directed toward renewables (4 trillion USD), with a third of this amount going to wind power, nearly $30 \%$ to solar power (mainly photovoltaic generation), and about a quarter to hydraulic power industry. While OECD (Organization for Economic Cooperation and Development) countries absorb 60\% of investments in energy efficiency ( $\$ 5$ trillion), non-OECD countries absorb more investments in low-carbon technologies (\$2.7 trillion) (International Energy Agency, 2015).

At the same time, the profile of climate risk and opportunities for MNEs could change significantly due to the physical impacts of climate change, climate policies, and new technologies. A 2015 study by The Economist estimates the impact of climate change risk on the world's total stock of assets under management to be between $\$ 4.2$ trillion and $\$ 43$ trillion in the 21 st century (The Economist Intelligence Unit, 2015). The study highlights that most of the impact on future 
assets will come from weaker growth and lower overall asset returns. This suggests that investors will not be able to avoid the risks associated with climate change by moving away from certain asset classes, as a wide range of assets could be affected. Therefore, both investors and the MNEs in which they invest should consider climate change in their long-term strategies and capital allocation. MNEs that invest in activities that may not be viable in the long term are likely to be less resilient to the transition to a low-carbon economy. Compounding the impact on long-term returns is the risk that current valuations inadequately account for climate risks due to insufficient information. Thus, long-term investors need proper information on how MNEs are preparing for the transition to a low-carbon economy. As the transition to a low-carbon economy requires significant and, in some cases, disruptive changes to sectors of the economy and industry in the short term, contemporary economic thought is interested in the implications for the global financial system, especially in preventing financial cataclysms and sudden losses in asset values.

\section{Typology and impact of climate risks}

To make more informed financial decisions, international investors, creditors and insurance companies need to understand how the risks and opportunities associated with climate change may affect the future financial position of MNEs as reflect-ed in their financial reports. While virtually all sectors of the economy are affected by climate change, the level and type of exposure to climate change risks varies by sector, industry, and geography.

According to the work of the Financial Stability Board's Task Force on Climate-Related Financial Disclosures, climate risks fall into two main categories: (1) transit risks associated with the transition to a low-carbon economy, and (2) physical risks associated with the physical effects of climate change (Task Force on Climaterelated Financial Disclosures, 2017).

\section{(1) Transit risks}

The transition to a low-carbon economy can lead to significant political, legal, technological, and market changes to meet climate change adaptation requirements. Depending on the nature, speed, and direction of these changes, transit risks can have varying levels of financial and reputational impact on MNEs.

\section{Political and legal risks}

Climate change policies continue to evolve. Their goals generally fall into two categories, namely policy actions designed to limit the negative effects of climate change, and policy actions designed to promote adaptation to climate change. Some examples include implementing $\mathrm{CO}_{2}$ pricing mechanisms to reduce greenhouse gas emissions, shifting energy use to lower-emission sources, adopting energy-efficient solutions, encouraging more efficient water use measures, and promoting more sus-tainable land use practices. The risks associated with policy change and their finan-cial impact depend on the nature and timing of the policy change.

Another important risk is litigation or legal risk. The past few years have seen an increase in lawsuits filed by property owners, municipalities, states, insurers, shareholders, and public interest organizations related to climate change (Law360, 2016). Reasons for such litigation include the MNE's failure to mitigate climate change, failure to adapt to climate change, and lack of information about significant financial risks. As the costs of climate change increase, the risk of litigation may also increase.

\section{Technological risk}

Technological improvements or innovations that support the transition to a low-carbon, energyefficient economic system can have a significant impact on MNEs. For example, the development and use of new technologies such as renewable energy, batteries, energy efficiency, and carbon capture and storage will affect the competitiveness of some MNEs, their production costs, their supply chain, and ultimately the demand for their products and services from end users. New technologies displace old systems and destroy some parts of the existing economic system, following a process of "creative destruction". The timing of technology development and deployment is a key uncertainty in technology risk assessment.

Market risk

While the factors affecting markets as a result of climate change are varied and complex, one of the main ones is the changing supply and demand for certain goods, products, and services as the risks and opportunities associated with climate change are increasingly taken into account.

Reputational risk

Climate change has been identified as a potential source of reputational risk associated with changes 
in consumer or public perception of the MNE contribution to the transition to a low-carbon economy.

\section{(2) Physical risks}

Physical risks related to climate change can be caused by sudden events (acute) or long-term (chronic) climate change. Physical risks can have financial consequences for GNP, such as direct damage to assets and indirect consequences from supply chain disruptions. GNP's financial results may also be affected by changes in water availability, sources and quality, food security, and extreme temperature fluctuations affecting MNE's facilities, operations, supply chain, transportation needs, and employee safety.

\section{Acute risk}

Acute physical risks refer to risks that are eventdriven, including the increased severity of extreme weather events such as cyclones, hurricanes, or floods.

\section{Chronic Risk}

Chronic physical risks refer to long-term changes in climate patterns (e.g., sustained temperature increases) that can cause sea level rise or chronic heat waves.

\section{Typology and impact \\ of climate opportunities}

Efforts to adapt to climate change also create opportunities for MNEs, such as through resource efficiency and cost savings, introduction of lowemission energy sources, development of new products and services, access to new markets, and strengthening supply chain resilience. Climatic capabilities vary by region, market, and industry in which MNE operates.

\section{Resource efficiency}

There is a growing body of evidence and examples of MNEs successfully reducing operating costs by improving the efficiency of production and distribution processes, particularly through energy efficiency (Copenhagen Energy Efficiency Center, UNEP and DTU Partnership, 2016). Such measures can lead to direct savings of GNP in the medium and long term and a global effort to curb emissions (Environmental Protection Agency Victoria, 2020). Innovations in emerging technologies contribute to this transition; such innovations include the development of efficient heating solutions, LED lighting technologies and industrial motors, the modernization of buildings, the use of geothermal energy and the development of electric vehicles.

\section{Source of energy}

According to the International Energy Agency, to meet global emission reduc-tion goals, the world's economic actors will need to shift a significant share of energy production to lowemission alternatives, such as wind and solar generation, wave power, hydro and nuclear power, geothermal energy, biofuels, and carbon capture and storage. Since 2012, investments in renewable energy capacity have exceeded investments in fossil fuel production (International Energy Agency, 2016). The trend toward decentralization of clean energy sources, rapid cost reductions, increased storage capacity, and further global deployment of these technologies are important. MNEs that shift energy use to low-emission energy sources have the potential to save on annual energy costs.

Products and services

Organizations that innovate and develop new low-emission products and services can improve their competitive position and benefit from changing consumer and producer preferences. Some examples include consumer products and services that pay more attention to a product's carbon footprint in their marketing and labeling (e.g., travel, food, beverage and consumer products, fashion and recycling services), and manufacturers' products that focus on reducing emissions (e.g., supply chain energy efficiency measures).

\section{Markets}

MNEs that are actively seeking opportunities in new markets or in new types of assets can diversify and better position themselves for the transition to a low-carbon economy. In particular, MNEs have opportunities to access new markets through collaboration with governments, development banks, small local businesses, and community groups in developed and developing countries in the process of transitioning to a lowcarbon economy. New opportunities can also come from underwriting or financing green bonds and infrastructure (e.g., low-emission energy production, energy efficiency, grid connection or transportation networks).

\section{Climate resilience}

The concept of climate resilience implies that MNEs develop the ability to adapt to climate change in order to better manage the risks associated with it and seize opportunities, 
Vol. 2 No. 3, 2021

Green, Blue \& Digital Economy Journal

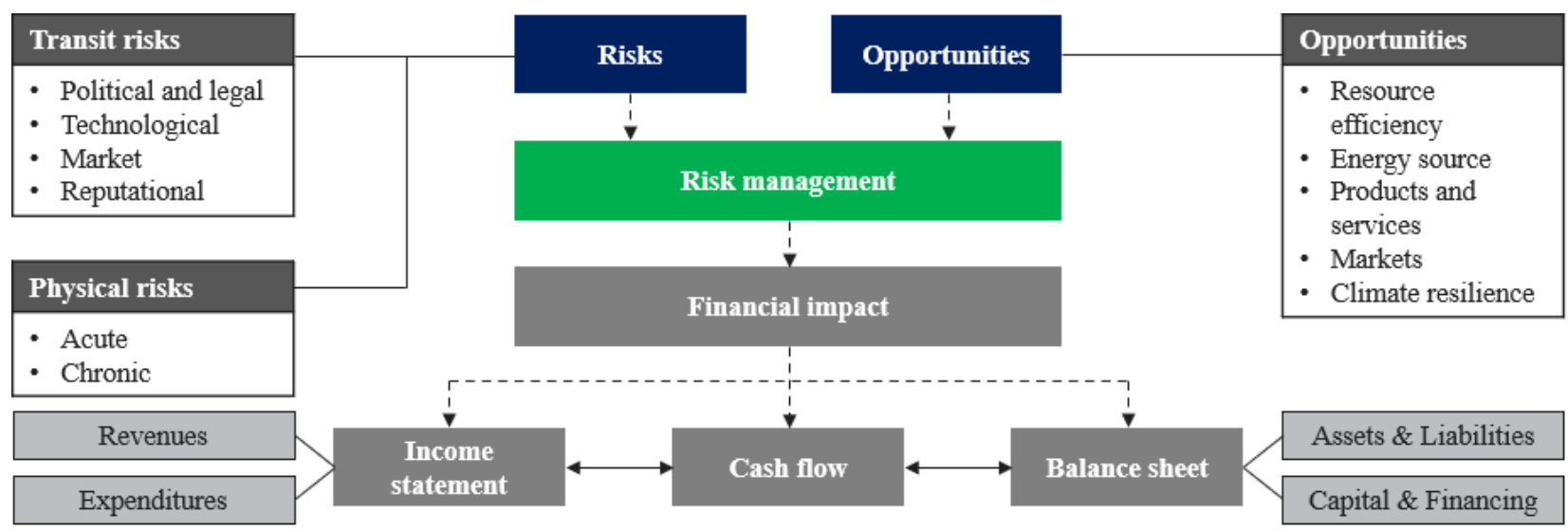

Figure 1. Interdependence and impact of climate risks and opportunities on the financial condition of MNEs

including the ability to respond to transient and physical risks. Opportunities include efficiency, designing new production processes, and developing new products. Climate resilience opportunities may be particularly relevant for MNEs with long-lived fixed assets or extensive supply or distribution networks, for those MNEs that are critically dependent on utilities and infrastructure networks or natural resources in their value chains, and for those MNEs that may require long-term financing and investment.

\section{Assessing the financial impact of climate risks and opportunities}

To make more informed financial decisions, investors, lenders, and insurance underwriters need to understand how climate risks and opportunities may affect the future financial position of MNEs as reflected in their income statements, cash flows, and balance sheets. While virtually all sectors of the economy are affected by climate change, the level and type of exposure to climate risks varies by sector, industry, geography, and MNEs. Figure 1 presents a diagram of the interdependence and impact of climate risks and opportunities on the financial condition of MNE.

The financial impact of climate change on MNEs is determined by the specific climate risks and opportunities to which MNEs are exposed, as well as their strategic and risk management decisions (i.e., mitigation, transfer, acceptance, or control) and use of those opportunities.

\section{Conclusions}

The fundamental trends of the last decade related to climate change, as well as interstate and global economic campaigns to slow it down, are creating a powerful determinant for multinational enterprises (MNEs) in corporate governance, risk management and sound management of climate risks and opportunities.

For some EU countries, it will soon become mandatory to highlight climate risk management principles and approaches in annual reports. Internal models are being developed to show the impact of climate change on the business of MNEs (e.g. an increase of $1.5^{\circ} \mathrm{C}, 2^{\circ} \mathrm{C}, 4^{\circ} \mathrm{C}$ in total temperature). A vivid example of the impact of climate risks is the warm winter of 2019-2020 in Europe. Many European companies operating in the gas market entered the heating season with their most filled gas storage facilities and faced a liquidity problem. Traditionally, they pumped gas in the summer, and at the beginning of the heating season they began to receive cash flows by selling natural gas on the market. With the onset of the abnormal heat wave, the price of natural gas and the level of its consumption decreased. To avoid a liquidity crisis, companies had to raise additional funds.

Climate risks already have a clear monetary value today. Modern, efficient businesses should build an effective system for managing such risks, which, in addition to its direct effect on MNEs, would be an important signal to society, regulators, and investors. And this, in turn, can reduce the cost of attracted foreign capital. 


\section{References:}

The Economist Intelligence Unit (2015). The Cost of Inaction: Recognizing the Value at Risk from Climate Change. Available at: https://impact.economist.com/perspectives/sites/default/files/The\%20cost\%20 of\%20inaction_0.pdf

United Nations Framework Convention on Climate Change (2016). The Paris Agreement. Available at: https://unfccc.int/process-and-meetings/the-paris-agreement/the-paris-agreement

International Energy Agency (2015). Energy Climate and Change. World Energy Outlook Special Briefing for COP21. Available at: http://climateknowledge.org/figures/Rood_Climate_Change_AOSS480_ Documents/IEA_COP21_Paris_Briefing_IntEnerAgen_2015.pdf

Task Force on Climate-related Financial Disclosures (2017). Recommendations of the Task Force on Climate-related Financial Disclosures. Available at: https://assets.bbhub.io/company/sites/60/2021/10/ FINAL-2017-TCFD-Report.pdf

Law360 (2016). Emerging Trends In Climate Change Litigation. Available at: https://www.law360.com/ articles/766214/emerging-trends-in-climate-change-litigation

Copenhagen Centre on Energy Efficiency, UNEP DTU Partnership (2016). Best Practices and Case Studies for Industrial Energy Efficiency Improvement. Available at: https://europa.eu/capacity4dev/unep/ documents/best-practices-and-case-studies-industrial-energy-efficiency-improvement

Environmental Protection Agency Victoria (EPA Victoria) (2020). How to improve resource efficiency in your business. Available at: https://www.epa.vic.gov.au/for-business/how-to/lower-environmentalimpact-business/improve-resource-efficiency-business

International Energy Agency (2016). Global energy investment down 8\% in 2015 with flows signaling move towards cleaner energy. Available at: https://www.iea.org/news/global-energy-investment-down-8-in2015-with-flows-signalling-move-towards-cleaner-energy 